\title{
Techno-economic Analysis of a Wind-Diesel Hybrid Power System in the South Algeria
}

\author{
Khaireddine Allalia*, El-Bahi Azzaga and Hocine Labara \\ 'Laboratoire d'Electrotechnique d'Annaba, Badji Mokhtar University-Annaba, P.O.Box 12, \\ Annaba 23000, Algeria
}

\begin{abstract}
The electrical energy is often produced with the help of diesel generators in isolated areas in the Saharan region. While the latter requiring relatively little investment because is generally expensive to exploit due to the transportation to remote areas adds extra cost, significant fuel consumption and relatively high maintenance cost, etc. Moreover, the electricity production by the diesel is ineffective, presents significant environmental risks. But these isolated areas have significant wind energy potential; which is good position for the exploitation of clean and sustainable wind energy. The use of wind-diesel power system is widely recommended especially to reduce fuel consumption and in this way to reduce system operating costs and environmental impact. The subject of this paper is to present the techno-economic analysis of a wind-diesel hybrid power system. In this context, the contribution envisaged with this research is to collaborate on the optimal design of hybrid power system including a wind turbine generator, a diesel generator and an energy storage system for powering a continuous way an isolated site in the South Algerian that installed power $120 \mathrm{~kW}$.This system has a high control strategy for the management of different power sources (wind, diesel, battery) that depending to weather conditions, especially wind speed values and the power demanded by the consumer load.
\end{abstract}

Keywords: renewable energy, hybrid system, isolated grid, management, simulation

Article History: Received January February 25, 2015; Received in revised form April 19, 2015; Accepted May 17, 2015; Available online

How to Cite This Article: Allali, K. , Azzaga, E-B. and Labara, H., (2015) Techno-economic Analysis of a Wind-Diesel Hybrid Power System in the South Algeria. International Journal of Renewable Energy Development, 4(2): 137-142

http://dx.doi.org/10.14710/ijred.4.2.137-142

\section{Introduction}

In recent years, the world climate change and global warming issues have been greatly debated by researchers and environmentalists. This is due to the growth of industrialization and world population which results in the increase of electricity demand especially the conventional electricity generation using the natural resources.

Energy is one of the major inputs for the economic development of any country. In the case of the developing countries, the energy sector assumes a critical importance in view of the ever increasing energy needs requiring huge investments to meet them. The growth of the world's human population has created several problems. One of them is global warming caused by the abundance of $\mathrm{CO}_{2}$ in the atmosphere. Many of these gases are produced from electrical plants burning fossil fuel all over the world. To reduce these emanations out into the atmosphere alternative sources of energy must be used. In the last two decades solar energy and wind energy has become an alternative to traditional energy sources. These alternative energy sources are non-polluting, free in their availability and renewable (Antonio et al 2011). Therefore, the development of wind turbines is a major investment in research technology. The systems that produce electrical energy from the wind can be an alternative to technological and economic exhaustible energy sources.

In isolated areas such as the Algerian Sahara (Adrar, Bechar, In Salah, Timimoun, Tindouf, Amenas, etc), electrical energy is often produced with the help of diesel generators. Moreover, the electricity production by the diesel is ineffective, presents significant environmental risks (spilling), contaminates the local air and largely contributes to GHG emission. In all, we 
estimate at $16086 \mathrm{~kg} /$ year GHG emission resulting from the use of diesel generators for the subscribers of the autonomous networks in Algeria (Tammam et al. 2012), (Saheb-Koussa et al. 2010).

Since the constitution of Kyoto Protocol aspiring stabilization of greenhouse gas concentrations in the atmosphere at a level that would prevent dangerous anthropogenic interference with the climate system, the decrease of the greenhouse gas emission by not damaging the economic performance has become a primary issue. As a remedy, the use of renewable energy source instead of fossil energy types and encouragement of energy saving technologies as a supplementary policy were suggested. In addition, whether foreign direct investment (FDI) helps to decrease energy intensity and greenhouse gas emission in the host country were argued in the literature (Yildirim 2014).

But numerous isolated areas have significant wind energy potential. It is then interesting to associate with a diesel some wind generators as diesel electricity is generally more expensive than wind electricity. To reduce fuel consumption and power variations of the diesel, an energy storage system can be associated with the wind-diesel system (Leclercq et al. 2003).

The objective of this work is to combine these diesel generators (DG) with wind turbine generators (WTG) plant sized to the needs of consumption, while providing continuous high quality electric power. The main goal with wind diesel hybrid system (WDHS) is to reduce fuel consumption and in this way to reduce system operating costs for economic purpose and environmental impact. This system equipped with a control system, a proper control strategy has to be developed to take full advantage of the wind energy during the periods of time.

\section{Geographical and meteorological data of the studied site}

\subsection{Geographical situation}

The studied site located in Adrar region with geographical coordinates $\left(27^{\circ} 59^{\prime} \mathrm{N}, 0^{\circ} 11^{\prime} \mathrm{W}, 263 \mathrm{~m}\right)$. Adrar state situated in the extreme Algerian South-West extends over $427968 \mathrm{~km}^{2}$ about (1/5) of the country.

\subsection{Meteorological data}

Our study essentially depends on the wind speed. data. The climate data of wind speed used in this section are average of wind speed measured at the site of Adrar and collected from the weather station of the Renewable Energy Research Unit in Saharian Medium (URER.MS) for the year 2012 (URER.MS 2012) (See Table 1 below).
Tabel 1

Monthly mean wind speed for Adrar region

\begin{tabular}{|c|c|c|c|c|c|c|c|c|c|c|c|c|}
\hline 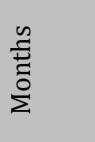 & $\begin{array}{l}\vec{\Xi} \\
\stackrel{\vec{\Xi}}{\Xi} \\
\underline{\Xi}\end{array}$ & 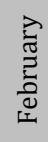 & $\begin{array}{l}\frac{\pi}{0} \\
\text { ¿ } \\
\Sigma\end{array}$ & $\overline{\bar{z}}$ & $\sum^{\vec{\pi}}$ & $\Xi$ & $\vec{\Xi}$ & 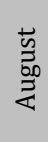 & 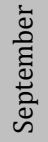 & $\begin{array}{l}\bar{\Xi} \\
\overline{0} \\
\overline{0} \\
0\end{array}$ & $\begin{array}{l}\bar{\Phi} \\
\bar{\Xi} \\
\overline{0} \\
\text { o } \\
z\end{array}$ & $\begin{array}{l}\dot{\bar{\Xi}} \\
\bar{\Xi} \\
\bar{\Xi} \\
\mathscr{\Xi}\end{array}$ \\
\hline $\begin{array}{c}v \\
(\mathrm{~m} / \mathrm{s})\end{array}$ & $\underset{f}{+}$ & $\underset{\tilde{N}}{\tilde{N}}$ & $\begin{array}{l}\text { L } \\
\stackrel{0}{0}\end{array}$ & $\prod_{n}^{m}$ & $\stackrel{\widehat{N}}{\text { - }}$ & $\stackrel{\widehat{N}}{\text { L }}$ & $\stackrel{\infty}{\stackrel{\infty}{N}}$ & $\underset{\xi}{F}$ & $\begin{array}{l}\vec{\sigma} \\
\stackrel{+}{*}\end{array}$ & $\stackrel{\infty}{+}$ & $\begin{array}{l}0 \\
\infty \\
+\end{array}$ & $\begin{array}{l}\infty \\
\text { ํㅗ } \\
\text { Ln }\end{array}$ \\
\hline
\end{tabular}

\section{Wind potential in Algeria}

The wind energy mainly depends on geographic and weather conditions and varies from time-to-time. The wind map of Algeria estimated at $10 \mathrm{~m}$ above the ground is shown in Fig.1, it shows that the highest wind speeds are distributed in the south while the north is generally less windy. It was found also that the south western region has a great potential with speeds exceeding $4 \mathrm{~m} / \mathrm{s}$ for the site of Bechar, $5 \mathrm{~m} / \mathrm{s}$ for the site of Tindouf and even above $6 \mathrm{~m} / \mathrm{s}$ for the site of Adrar. The fact that the south western region of the country has a significant wind potential can be attributed to two factors: the first is that it is located in an area of pressure difference (wind in the latitudes near $30^{\circ} \mathrm{N}$ ). The second is that it is close to the Atlantic Ocean (weather disturbances reaches the region with high intensity) (Hamane et al. 2000).

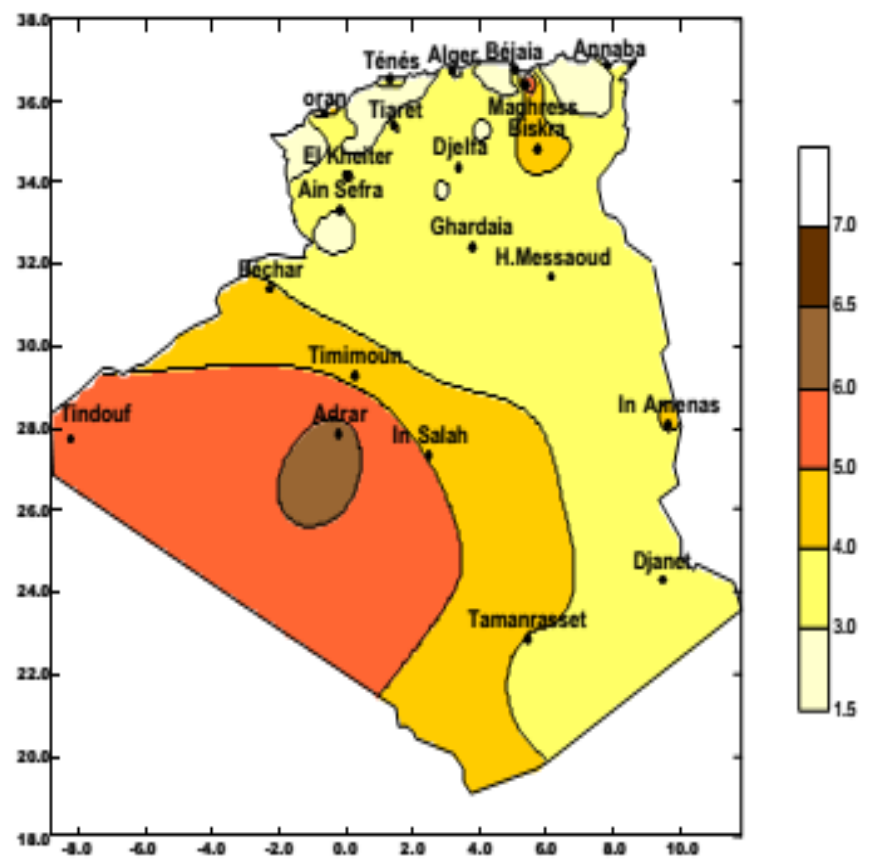

Figure1 Map of the average annual wind speed at $10 \mathrm{~m}$ above ground $(\mathrm{m} / \mathrm{s})$. 


\section{Hybrid system overview}

In this study, Fig. 2 shows the configuration considered in this paper. This configuration consists of wind turbine generator (WTG), diesel generator (DG), battery bank, consumer load, power electronic converters (AC/DC rectifier, DC/AC inverter), monitoring system, distributed control system (DCS), switches and relays, controller and other accessory devices and cables (Elkhatib et al. 2010), (Ibrahim et al. 2011).

A "Wind Diesel Hybrid System" with storage system as illustrated in Fig. 2, comprising a Diesel Generator (DG), a Wind Turbine Generator (WTG), the consumer Load, a Ni-Cd Battery based Energy Storage System (BESS) and a Distributed Control System (DCS). The WDHS have a third operation mode is detailed in the next section.

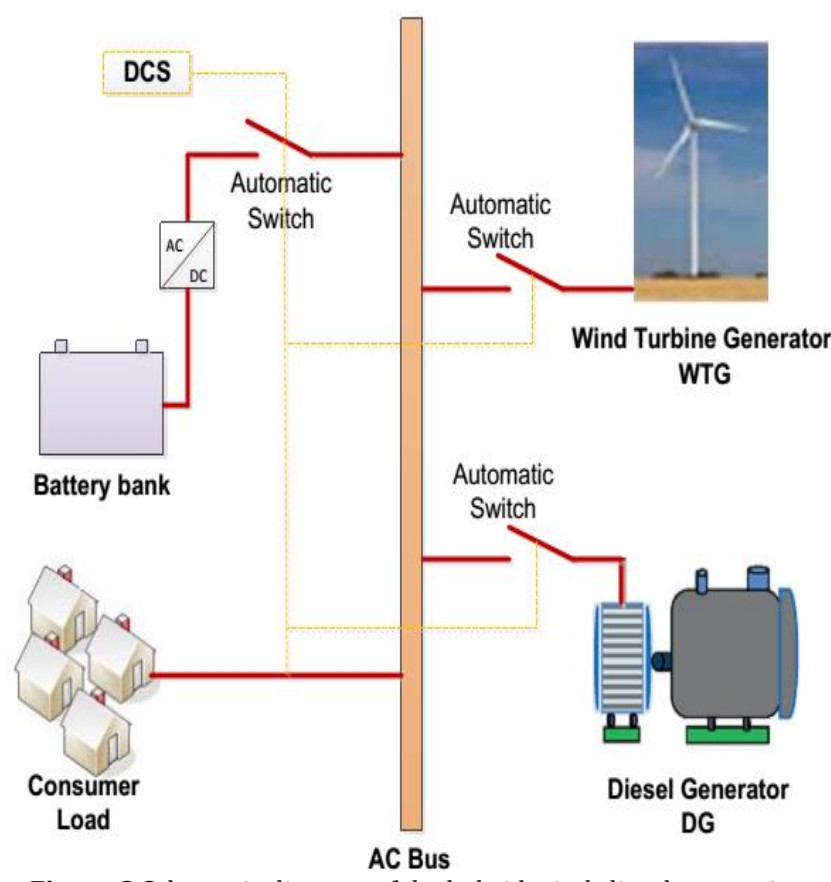

Figure 2 Schematic diagram of the hybrid wind-diesel generation power system.

\section{Operation modes of wind-diesel hybrid system}

The WDHS is classified as being High Penetration (HP), (Ibrahim et al. 2011). HP-WDHS have three modes of operation: Diesel Only (DO), Wind Diesel (WD) and Wind Only (WO) as follows:

1. Weak winds ( $v_{\omega} \leq 3 \mathrm{~m} / \mathrm{s}$ ): Diesel Only (DO).

2. Moderate winds $\left(3 m / s<v_{\omega} \leq 10 m / s\right)$ : Wind and Diesel (WD) in service.

3. Strong winds $\left(v_{\omega}>10 \mathrm{~m} / \mathrm{s}\right)$ : Wind Only (WO).

The HP-WDHS mode is illustrated in Fig. 3.

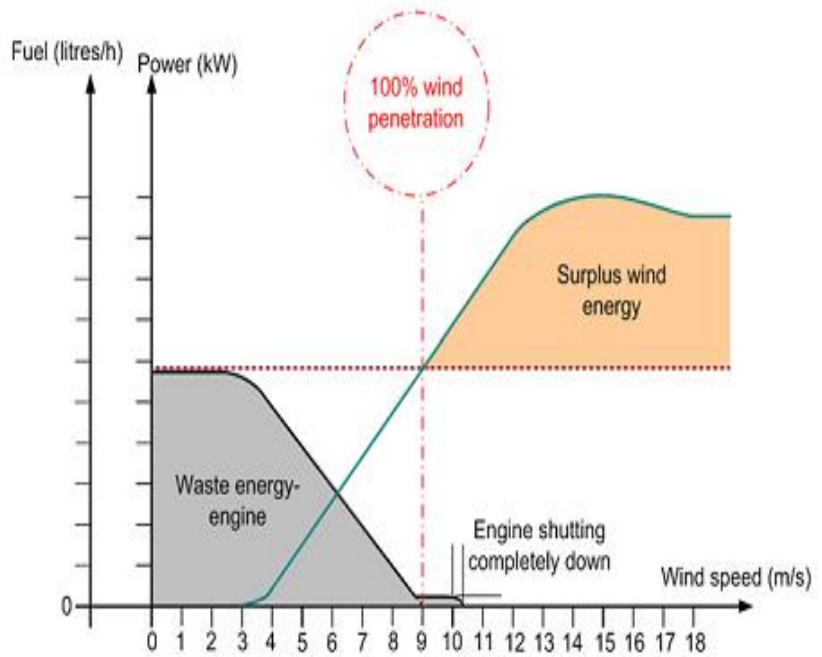

Figure 3 Wind and diesel power variation with wind speed for a highpenetration.

\section{Installation presentation}

Selected elements for our hybrid system are:

\subsection{Wind turbine generator (WTG)}

The wind turbine chosen is the mark NORDEX N27150 , is a horizontal axis turbine with rated power 150 $\mathrm{kW}$, and three blades, the rotor acts in the direction of the wind (Nordex 2015).

\subsection{Diesel generator (DG)}

The diesel generator chosen is the type FG Wilson P150-1; it develops a maximum power of $120 \mathrm{~kW}$, (Wilson 2014).

\subsection{Battery energy storage system (BESS)}

The Ni-MH batteries have very similar properties to $\mathrm{Ni}-\mathrm{Cd}$ batteries, Ni-MH batteries have shorter useful lifetime, but more power capability than $\mathrm{Ni}$-Cd type (Linden et al. 2002). Cadmium is a toxic heavy metal with mandatory provisions for disposal not so easy to fulfil in remote areas. Therefore, this environmental aspect recommends selecting $\mathrm{Ni}-\mathrm{MH}$ batteries for this present paper.

\section{The proposed control system strategy}

For a multi-source energy system, a power flow management strategy is needed. According to wind speed values and the power demanded by the consumer load. The power management strategy used in this study is according to the flow chart shown in Fig. 4. (Sedaghat et al. 2012).

After input meteorological data and required power by load, the program has calculate the generated power 
by WTG and check the first condition $\left(v_{\omega} \leq 3 \mathrm{~m} / \mathrm{s}\right)$, if the condition is not checked the program has been verified secondly condition $\left(v_{\omega} \leq 10 \mathrm{~m} / \mathrm{s}\right)$; in the DO mode, the DG supplies the active and reactive power demanded by the consumer load (in this mode the WTG is turned off). In the WD mode, both the DG and WTG supply the active and reactive power. In the wind only (WO) mode, only the WTG supplies the active power (DG is disconnected): if the power produced by the WTG $\left(P_{\mathrm{T}}\right)$ can be greater than that consumed by the consumer load $\left(P_{\mathrm{L}}\right)$, in this case, the excess wind energy is stored in the battery bank. The energy storage can be used if there is a problem for the two sources of electricity production (wind energy and diesel).

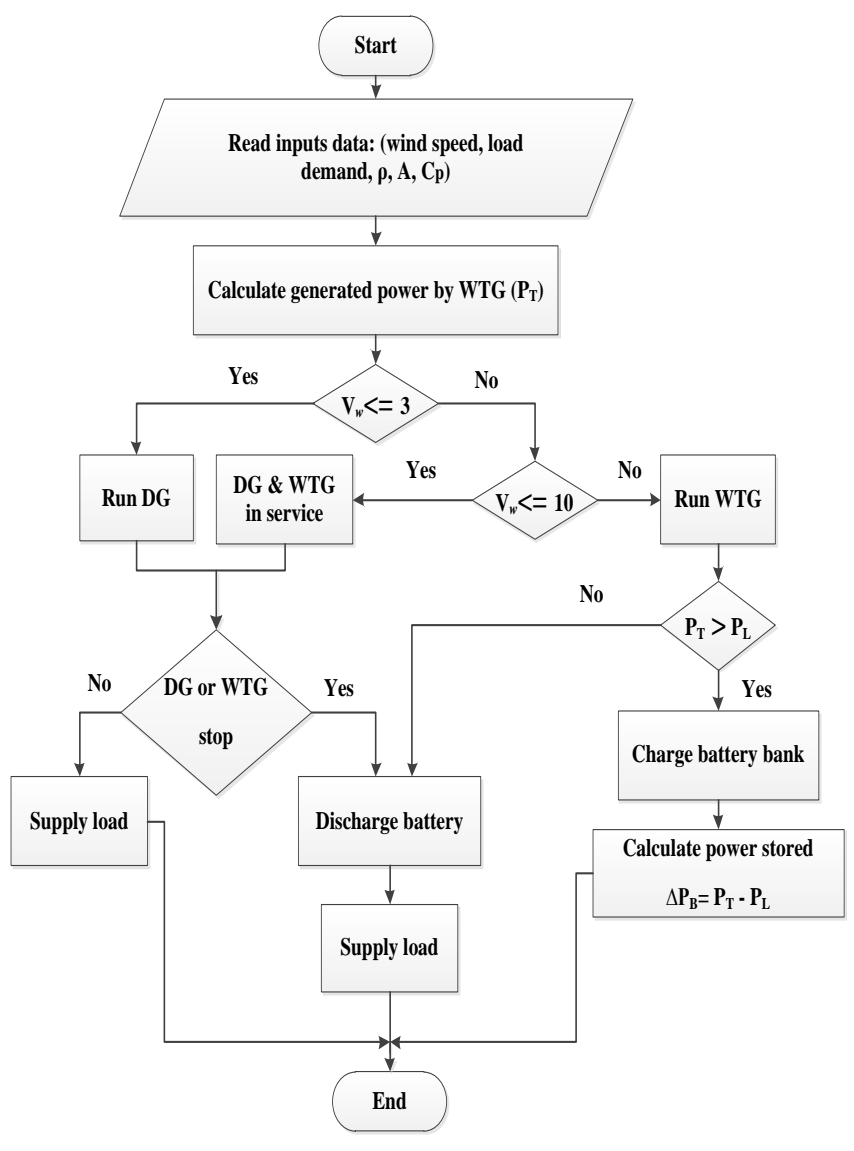

Figure 4 Main flow chart.

\section{Simulation results and discussions}

From Table 1, the highest wind speed was in July $(7.78 \mathrm{~m} / \mathrm{s})$. Fig. 5 shows the average daily wind speed for the considered site in July.

Load profile study and determination is the first step for the design of any electric power system. The behaviour of consumers and the operation of different electrical devices are the parameters that determine the load profile curve.

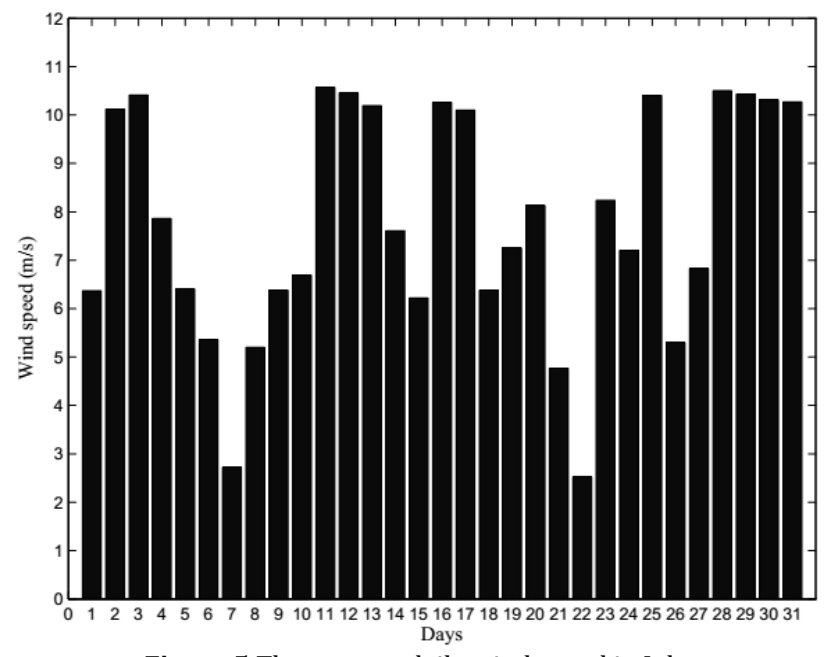

Figure 5 The average daily wind speed in July.

Fig. 6 shows the load profile adopted in this study. This profile is considered to be the same for all the days of the year with peak load as $98 \mathrm{~kW}$.

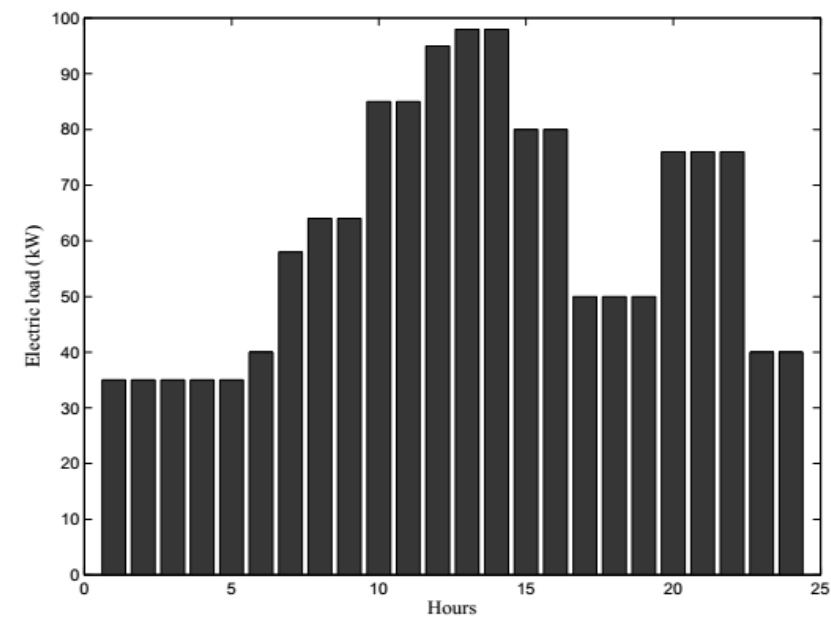

Figure 6 Daily load profile.

Fig. 7 shows electricity produced by wind turbine generator and diesel generator. The wind turbine generator only supplies energy during $12^{\text {th }}$ days; in these cases the generated power $\left(\mathrm{P}_{\mathrm{T}}\right)$ is greater than the require power by the consumer load $\left(\mathrm{P}_{\mathrm{L}}\right)$. So, the surplus wind energy will be stored in battery bank. But, on July $7^{\text {th }}$ and $22^{\text {nd }}$ the supply power is ensured by diesel generator only because the wind speed is less than $3 \mathrm{~m} / \mathrm{s}$. The battery bank is used only when the renewable source and/or the conventional diesel power system are not able to satisfy the load demand, also when the DG or WTG broke down. The estimate equation used for calculate generated power is expressed below:

$$
P=\frac{1}{2} \rho \cdot S \cdot v_{\omega}^{3} \cdot C_{p}(\lambda, \beta)
$$


Where:

$\rho$ is the air density $\left(\mathrm{kg} / \mathrm{m}^{3}\right), \mathrm{S}$ the area swept by

turbine blades, $v_{\omega}$ the wind speed, $C_{p}$ the rotor power coefficient, $B$ the pitch angle.

In this paper, $C_{p}$ is the power coefficient of rotor has been defined by Eq. (2), (B. Sedaghat et al. 2012). Power coefficient is a function of tip speed ratio $\lambda$ defined by Eq. (3) and pitch angel $\beta$. The wind turbine considered in this work is stall controlled, so pitch angel is kept constant, is considered zero where the $C_{p}$ value would be 0.48 and $C_{p}$ is a function of $\lambda$ (Kassem Ahmed M et al. 2012).

$$
\begin{aligned}
& C_{p}=(0.44-0.0167 \beta) \cdot \sin \left[\frac{\frac{\pi}{2}(\lambda-3)}{7.5-0.15 \beta}\right]-(\lambda-3) \cdot(0.00184 \beta) \\
& \lambda=\frac{\Omega_{r} \cdot R}{\nu_{\omega}}
\end{aligned}
$$

Where $\Omega_{\mathrm{r}}$ is the rotor rotational speed and R is the wind turbine rotor radius.

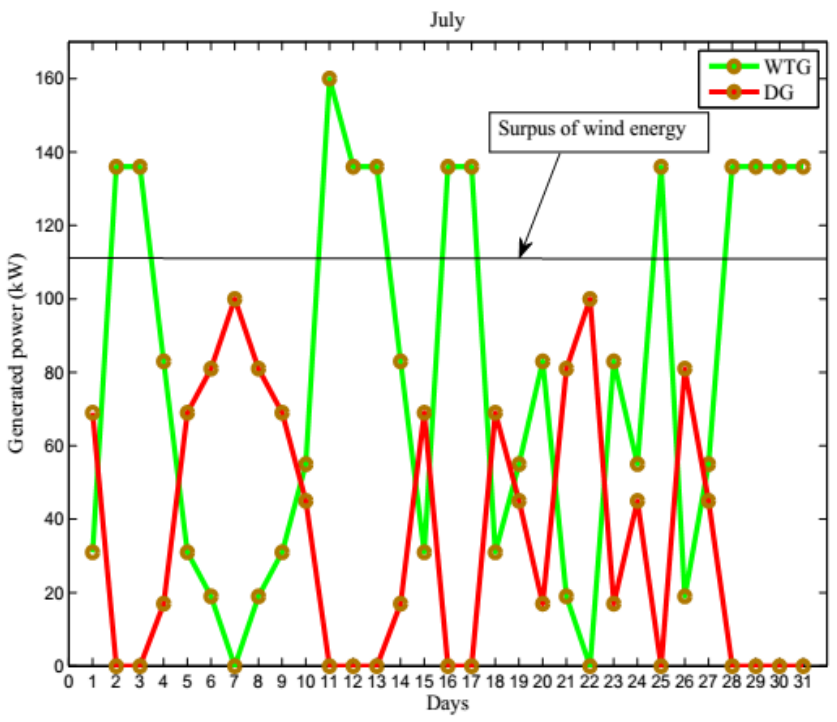

Fig. 7 The daily energy production by wind-diesel hybrid system.

The costs related to the hybrid wind-diesel power system is shown in Fig 8: the energy cost of WTG is greater than DG this is due to the number of operation of each system; the relationship used in this way is: Energy Cost WTG or DG = energy production by WTG or $\mathrm{DG} \times$ Cost of Energy (COE). In our study the COE is 5.958 DA/kWh. While the latter has the effect of fuel consumption and its impact on $\mathrm{CO}_{2}$ emissions as illustrate in Fig 9:

$\mathrm{CO}_{2}$ emission $=$ fuel consumption $\times$ Quantity of $\mathrm{CO}_{2}$ produced.

(In this work, the quantity of $\mathrm{CO}_{2}$ produced is $2.6 \mathrm{~kg} / I$ )
The cost of fuel consumption= fuel consumption (I) $\times$ Diesel fuel cost (13.7 DZA/l)

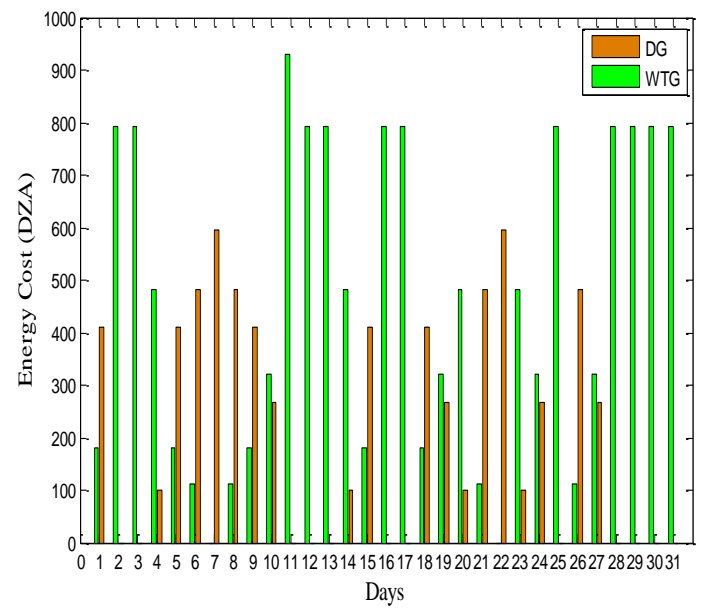

Fig. 8 Power generation costs.

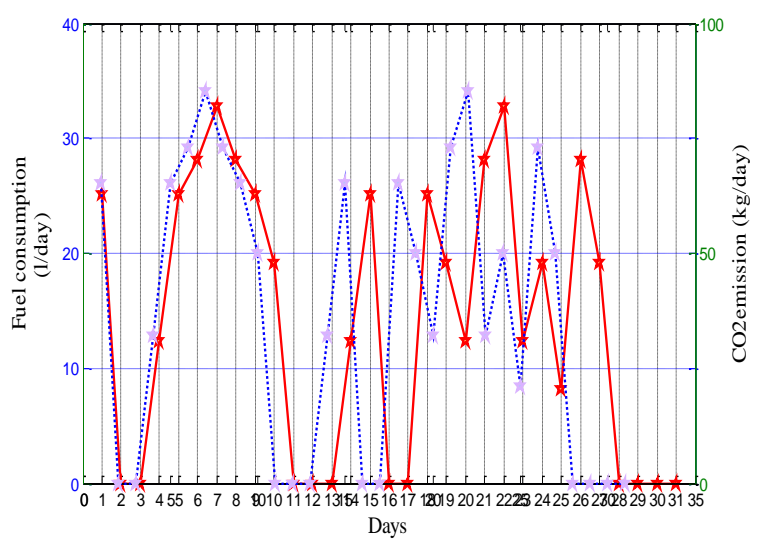

Fig. 9 Fuel consumption and $\mathrm{Co}_{2}$ emission by DG.

Compared to the conventional diesel power system, the wind-diesel power system is one of the best alternative solutions that has many advantages such as: more efficiency, relatively low maintenance cost and based on wind energy which is clean and economic inexhaustible energy source. Furthermore, the winddiesel power system is more environmentally friendly that has less $\mathrm{CO}_{2}$ emission.

The hourly fuel consumption of the diesel generator, $Q(t)(l / h)$ can be modeled by linear law based on output power required by the load (Ismail, $M$ et al. 2013):

$$
Q(t)=\alpha_{D} \cdot P_{D}(t)_{g e n}+\beta_{D} \cdot P_{D}(t)_{r a t}
$$

Where $\alpha_{D}(l / k W h)$ and $\beta_{D}(l / k W h)$ are coefficients of the consumption curve provided by the manufacturer while $\boldsymbol{P}_{D}(\boldsymbol{t})_{\text {gen }}(k W)$ and $\boldsymbol{P}_{D}(\boldsymbol{t})_{\text {rat }}(k W)$ are power generated and rated power of the DG. The values 
allocated to $\alpha_{D}$ and $\beta_{D} 0.246$ and $0.08145 \mathrm{l} / \mathrm{kWh}$, respectively and $P_{D}(t)_{\text {rat }}=120 \mathrm{~kW}$.

\section{Conclusion}

This paper presents a techno-economic analysis and the design of a complete hybrid system, consisting of wind turbine generator, a diesel generator and a battery system as a backup power source for a typical isolated area situated in Adrar region. We have demonstrated the electricity produced with the help of diesel generators is relatively inefficient, very expensive and responsible for the emission of Greenhouse Gas (GHG). The WDHS has a great potential technical, economical and ecological very promoter and very cost-effective compared to the traditional diesel system. This system has a good control strategy for the management of different power sources (wind, diesel, battery) that allowing optimizing the operation of the hybrid system, to take full advantage of the wind energy during the periods of time and to minimize diesel fuel consumption, in this way to reduce system operating costs and environmental benefits. Therefore, the wind-diesel power system is widely recommended especially for isolated sites that have significant wind energy potential. Hybrid diesel-wind power generation systems have a great potential in the application of providing energy supply for remote communities and facilities. Compared to the traditional diesel system, hybrid power plants can offer many advantages such as additional capacity, being more environmentally friendly, potential reduction of cost, etc

\footnotetext{
References

Sedaghat., A. Jalilvand., R. Noroozian (2012) Design of a multilevel control strategy for integration of stand-alone wind/diesel system, Electrical Power and Energy Systems, 35, 123-137.

D. Saheb-Koussa., M. Haddadi., M. Belhamel (2010) Etude de faisabilité
}

et optimisation d'un système hybride (Eolien-PhotovoltaÏqueDiesel) à fourniture d'énergie électrique totalement autonome, Journal of Fundamental and Applied Sciences. Vol. 2 (1), 84-95.

Elkhatib Kamal., Magdy Koutb., Abdul Azim Sobaih., Belal Abozalam (2010) An intelligent maximum power extraction algorithm for hybrid winddiesel-storage system, Electrical Power and Energy Systems, 32, 170-177.

H. Ibrahim., R. Younès., T. Basbous., A. Ilinca., M. Dimitrova, (2011) Optimization of diesel engine performances for a hybrid winddiesel system with compressed air energy storage, Energy, 36, 3079-91.

Ludovic Leclercq., Benoit Robyns., Jean-Michel Grave (2003) Control based on fuzzy logic of a flywheel energy storage system associated with wind and diesel generators, Mathematics and Computers in Simulation, 63, 271-280.

Luiz Antonio De Souza Ribeiro., Osvaldo Ronald Saavedra., Shigeaki Leite De Lima., José Gomes De Matos (2011) Isolated Micro-grids With Renewable Hybrid Generation: The Case Of Lençóis Island, IEEE Transactions on Sustainable Energy, Vol. 2, No. 1, January 2011.

Tammam Basbous., Rafic Younes., Adrian Ilinca., Jean Perron (2012) A new hybrid pneumatic combustion engine to improve fuel consumption of Wind-Diesel power system for noninterconnected areas, Applied Energy, 96, 459-476.

Weather station of the Renewable Energy Research Unit in Saharian Medium (URER-MS) Adrar, Algeria (2012). http://www.urerms.dz/.

Kassem Ahmed M, Yousef Ali M. (2011) Robust control of an isolated hybrid wind-diesel power system using Linear Quadratic Gaussian approach. Int Electr Power Energy Syst, 33: 1092100.

Hamane, L, Khellaf A. Wind energy resources in Algeria. Brighton: UK, 2000, 2352-2355.

D. Linden, T.B. Reddy (Eds.). Handbook of Batteries, 3rd ed. McGrawHill, ISBN: 978-0-07-135978-8, 2002.

Documentation NORDEX available online at (http://www.nordexonline.com). Accessed on 8 January 2015.

Documentation FG Wilson available online at: (http://www.FGWilsononline.com). Accessed on 16 December 2014.

Ertugrul YILDIRIM. (2014) Energy use, CO2 emission and foreign direct investment: Is there any inconsistence between causal relations?. Frontiers in Energy, 8(3): 269-278. M.S.

Ismail, M. Moghavvemi, T.M.I. Mahlia. (2013) Techno-economic analysis of an optimized photovoltaic and diesel generator hybrid power system for remote houses in a tropical climate. Energy Convers Manage, 69: 163-173. 